\title{
2006-581: RETENTION STRATEGIES IN SMALLER TECHNOLOGY MAJORS
}

\section{Janice Girouard, University of Hartford}

Janice Girouard serves as the Director of Student Services for the College of Engineering, Technology, and Architecture at the University of Hartford. She earned her BFA at the Hartford Art School, University of Hartford in 1978 and her M.Ed. at the College of Education, Nursing and Health Professions, University of Hartford in 2004.

\section{Ivana Milanovic, University of Hartford}

Ivana M. Milanovic received her Ph.D. in Mechanical Engineering from Polytechnic University, NY, and M.S. and B.S. from University of Belgrade in Yugoslavia. Her research on vortical flows has been published in journals of the AIAA. Dr. Milanovic is also member of the ASME, AIAA and ASEE. As an ASME member, Dr. Milanovic is active on Fluid Mechanics Technical Committee co-organizing symposia, forums, and poster sessions. She was an intern of the ASME Minority Leadership program and has served on the ASME board of Board on Engineering Education. Her honors include Outstanding Teacher Award of the University of Hartford, NASA-OAI Faculty Fellowships, Polytechnic University Graduate Fellowship, and Zonta International Amelia Earhart Fellowship Award. Dr. Milanovic served as the Chair of the Mechanical and Audio Engineering Technology Department at the Ward College of Technology in the period 2002-2005. She is currently Program Director for Mechanical Engineering Technology in the Department of Mechanical Engineering at the College of Engineering, Technology, and Architecture.

\section{Natalie Segal, University of Hartford}

Prior to her appointment as a full-time teacher of technical communications at S. I. Ward College of Technology at the University of Hartford, Assistant Professor NATALIE SEGAL worked for more than 20 years as a technical writer and taught technical writing part-time at Ward College for eight years. She holds her Bachelor's Degree in English Education from the University of Connecticut, a Master's Degree in English from Trinity College and a Master of Fine Arts in Creative Writing from the University of Southern Maine. In addition to her fiction and poetry writing, Professor Segal is involved in research into the application of multiple intelligences theory in the college classroom.

\section{Dr. Sallie "Lee" Townsend, University of Hartford}

DR. SALLIE S. TOWNSEND is an optical physicist who earned her Ph.D. in physics at the University of New Hampshire and then worked for United Technologies as a theorist and computer modeler of high energy lasers and optical systems. After leaving United Technologies, she formed a small laser business. Her industrial work has led to five patents. For the last several years she has taught mathematics and physics at the Ward College of Technology, which recently was merged with the College of Engineering to form the College of Engineering, Technology, and Architecture at University of Hartford. This spring she will teach optics to graduate students in the College. 


\title{
RETENTION STRATEGIES IN SMALLER TECHNOLOGY MAJORS
}

\begin{abstract}
The technology programs in the College of Engineering, Technology, and Architecture at the University of Hartford vary widely in number of incoming students. The three smallest programs or majors, Computer Engineering Technology, Electronic Engineering Technology, and Mechanical Engineering Technology, each comprise fewer than 20 entering students a year. The larger programs, Architectural Engineering Technology and Audio Engineering Technology, each bring in about 40 or more entering students a year. The three smaller programs face issues retaining first-year students who typically come into the University with lower SAT scores, enroll in majors that are perceived to be more difficult and less 'fun,' and tend to be lost among the larger populations. However, we have devised strategies to engage students in those smaller majors, and those strategies appear to be working. In this paper, we will share our strategies and plans for future activities aimed at retaining and growing our student population in the three smallest majors in the College.
\end{abstract}

\section{Introduction}

Engineering and technology educators and administrators have written about retention issues extensively. ${ }^{1-9}$ An important factor in retention is the first-year experience. ${ }^{1}$ The body of work for increasing retention is differentiated by two types of instruction, one that offers lecture style, passive learning environments and the other that provides experiential learning with hands-on experience. Each institution should reflect and examine it's own internal dynamics and reasons why students leave engineering technology programs as suggested by the study. ${ }^{5}$ This impetus was the motivation for the assessment of retention issues in the smaller technology programs in the College of Engineering, Technology, and Architecture (CETA).

The technology programs in the newly merged College of Engineering, Technology, and Architecture at the University of Hartford vary widely in enrollments. The largest programs, Architectural Engineering Technology (AET) and Audio Engineering Technology (AuET), easily attract 40 or more students each year because they are unique and offer more opportunities to express creativity early in the course of study. Those two programs could consistently bring in more students if not for limits imposed by space and faculty considerations. In contrast, our three smaller programs, Computer Engineering Technology (CET), Electronic Engineering Technology (EET), and Mechanical Engineering Technology (MET), are found on many campuses, are related closely to Engineering disciplines, and are perceived to be more narrowly structured, restrictive, and demanding with only long-term rewards. ${ }^{2}$ These programs enroll no more than 20 students a year.

Beginning almost ten years ago, the authors noticed that the students in AET and AuET easily formed strong, major-specific communities that included study groups and informal support groups. Those students seemed to have a strong commitment to their programs and continuing their studies. CET, EET, and MET students did not form those communities and did not seem to have the same commitment as reflected in declining numbers. Though the students in these majors were in the same section of the same course, they were typically scattered among other 
majors in various sections, so they never identified one another as being in the same major. In addition, they did not share homework assignments and projects that would allow them to work together. Recognizing the situation, we made an effort to provide first-year students with at least one common technical course in each major, but the problem persisted. ${ }^{6-7}$

And the situation for to-be-determined majors (TBDs) is more difficult. They have no major with which to identify, no technical courses in common, no faculty member with whom to bond, at the same time that they need more guidance in order to determine which major they really want.

Believing that retention is strongly related to the culture of each College and having a problem to solve within some of our technology programs, and in an effort to actively engage students in forming their educational plan, we created, in 1996, a course titled Introduction to Engineering Technology (ET 111). In that course, we instruct students in, among other topics, the requirements for satisfactory academic progress and share strategies for getting the most out of their education, including selection of minors and preparation for graduate school. We also bring in guest speakers to give the students some exposure to industry. As far as creating student communities went, however, ET 111 enrollment was used to mix all the majors together to facilitate identification with the College rather than within the major. The unfortunate result was often that students from the larger majors dominated the class. ${ }^{1}$

In 2000, we began to offer a First-Year Interest Group (FIG), consisting of two linked courses that the same population of students takes together, in our case, Freshman Composition (EN 111) and Algebra and Trig for Technologists (MTH 112). We devised various instructional methods to support student learning. ${ }^{6}$ However, students from any major were free to enroll in the FIG; thus, there was still no encouragement for the students from the smaller majors to take the courses and bond. For instance, after both ET 111 and the FIG classes, the students from AET and AuET would hang around to talk to one another and the instructors, while others simply left the classroom, often alone. The students from the larger majors traveled together between classes, too, attended various functions together, and even got involved in student organizations together. The students from the smaller majors simply did not appear to be building identification with one another, the faculty, the College, or the University. Consequently, they were not staying at our College.

Therefore, retention remained an issue. While we claim that our advantage in being a small school is that students receive individual attention and form communities, our students were not engaging in collective activities within their majors, and numbers were declining. We needed to devise new strategies to increase our retention and not coincidently improve the first-year experience for our students.

\section{Strategies}

In spring 2004, we decided to cluster the CET, EET, MET, and TBD students in the same sections of ET 111, the FIG of EN 111 and MTH 112, and the first course in their major. The schedule changes were implemented in fall 2004 so that all the students now would track together through at least four out of five classes in their first semester. 
In the designated section of ET 111, we began to provide guidance directed toward the specific majors. We now invite the appropriate department chairs into the classroom and allow time for discussion. We particularly encourage students to ask questions and get to know their department chair because this person is the one who can provide the best academic guidance and, when appropriate, make necessary changes and accommodations in their programs.

In the fall 2005 semester, we added peer mentors to the ET 111 speaker list. The peer mentors are from the same majors as the freshmen, so they can address the students' concerns and encourage membership in professional societies while also reinforcing the information the faculty instructors provide. During their first class with the peer mentors, for example, students were observed actively participating in the class, taking notes, enthusiastically asking questions, and actually applauding the speakers. Several MET freshmen stopped their chair in the hallway after class to tell her how good the peer mentors were; the students were excited by the information they had received and wanted more. Though the faculty had given them the same information in some cases, the students gave the information more credibility because it came from their peers.

Enrolling the students from that one section of ET 111 in the FIG continues to encourage CET, EET, and MET students, along with the TBDs, to group and work together in their respective majors and helps us with instruction. Because we see the same students over multiple classes, we can observe them closely and share information that helps us in teaching them. For example, we noticed that several students consistently added when they should have multiplied in solving equations. The same students wrote papers in Composition that revealed their reluctance toward getting extra help. The FIG instructors discussed the information and found a way to individualize assistance for those students.

In addition to that micro-observation, the authors also have worked with students to provide connections to broader educational paths. We attempt to be open as the students express ambitions, then help them refine their career objectives and steer them toward the courses that will help them efficiently achieve their goals. For example, many of our students express an interest in graduate school. Because there are so few graduate degrees in technology, we work with them to make sure they take the proper courses to qualify for Masters programs in Engineering. In other cases, we have assisted students with diverse interests to pursue minors or associate's degrees in related fields or even contract majors. We know that one reason students and parents choose a smaller school is individualized attention and guidance, and we are seeing that such expectations must be met.

As a result of our efforts, over the course of two years, the authors have informally observed the MET students helping one another in the study area of the College, coming to their advisors for registration as a group - by choice - in order to make sure that they would be in the same sections of their spring classes, and proactively going as a group to the same tutors for assistance with classwork. The EETs and CETs are smaller groups than the METs and are slower to cluster, but in the fall of 2005, we observed those students behaving similarly. 
Insofar as TBDs are concerned, in the fall of 2004 we began to work more closely with them. We identified those students early in the semester and discussed courses in the various majors to help them determine their educational path. We discovered that some students believed they were or intended to be matriculated in a specific major but had been misclassified as TBDs. We identified those students, verified their information, and assisted them in completing the appropriate forms so that they would be advised properly as well as counted in their major. Therefore, by year's end, there were fewer TBDs, but we had retained a greater number of students by identifying them and addressing their needs.

\section{The Numbers}

The following tables represent the numbers of students in MET, CET, and EET over their first three semesters beginning in the fall of 2002.

Mechanical Engineering Technology

First to Second Semester Retention

\begin{tabular}{|l|c|}
\hline Fall & Freshman \\
\hline 2002 & 9 \\
\hline 2003 & 9 \\
\hline 2004 & 9 \\
\hline 2005 & 16 \\
\hline
\end{tabular}

\begin{tabular}{|c|c|}
\hline Spring & Freshman \\
\hline 2003 & 9 \\
\hline 2004 & 6 \\
\hline 2005 & 8 \\
\hline 2006 & 15 \\
\hline
\end{tabular}

Computer Engineering Technology

First to Second Semester Retention

\begin{tabular}{|l|c|}
\hline Fall & Freshman \\
\hline 2002 & 12 \\
\hline 2003 & 10 \\
\hline 2004 & 5 \\
\hline 2005 & 7 \\
\hline
\end{tabular}

\begin{tabular}{|c|c|}
\hline Spring & Freshman \\
\hline 2003 & 9 \\
\hline 2004 & 9 \\
\hline 2005 & 3 \\
\hline 2006 & 9 \\
\hline
\end{tabular}

First to Second Year Retention

\begin{tabular}{|l|c|}
\hline Fall & Freshman \\
\hline 2002 & 12 \\
\hline 2003 & 10 \\
\hline 2004 & 5 \\
\hline
\end{tabular}

\begin{tabular}{|l|c|}
\hline Fall & Sophomore \\
\hline 2003 & 3 \\
\hline 2004 & 6 \\
\hline 2005 & 1 \\
\hline
\end{tabular}

\begin{tabular}{|l|c|}
\hline Fall & Freshman \\
\hline 2002 & 9 \\
\hline 2003 & 9 \\
\hline 2004 & 9 \\
\hline
\end{tabular}$\quad$\begin{tabular}{|l|c|}
\hline Fall & Sophomore \\
\hline 2003 & 7 \\
\hline 2004 & 8 \\
\hline 2005 & 11 \\
\hline
\end{tabular}

\section{Electronic Engineering Technology}

First to Second Semester Retention

\begin{tabular}{|l|c|}
\hline Fall & Freshman \\
\hline 2002 & 2 \\
\hline 2003 & 8 \\
\hline 2004 & 4 \\
\hline 2005 & 11 \\
\hline
\end{tabular}

\begin{tabular}{|c|c|}
\hline Spring & Freshman \\
\hline 2003 & 2 \\
\hline 2004 & 7 \\
\hline 2005 & 6 \\
\hline 2006 & 10 \\
\hline
\end{tabular}

First to Second Year Retention

\begin{tabular}{|c|c|}
\hline Fall & Freshman \\
\hline 2002 & 2 \\
\hline 2003 & 8 \\
\hline 2004 & 4 \\
\hline
\end{tabular}

\begin{tabular}{|l|c|}
\hline Fall & Sophomore \\
\hline 2003 & 6 \\
\hline 2004 & 8 \\
\hline 2005 & 5 \\
\hline
\end{tabular}

While retention in EET and MET appears to be stable, CET does not. Nevertheless, we see changes in student behavior that represent positive trends. We are listening and responding to our students, they are listening and responding to us, they are bonding among themselves and with us and have become proactive in seeking avenues for expanding their educational opportunities. Thus encouraged, we are planning to create new initiatives that will eventually, we believe, be reflected in increasing numbers. 


\section{New Initiatives Proposed}

Now that the colleges of technology and engineering are merged, we are building a peer mentoring program for technology students like the one already created for engineering students, but we need to develop a strategy that encourages the students to meet regularly with their mentors. In the engineering program, all the students must take Engineering and Design (ES 143) in which the students are offered extra points on their grade if they have met regularly with their mentors outside of class. The obstacle in the technology programs is that there is no one course common to all majors except ET 111, which is graded Pass/No Pass. Among the proposals to resolve this issue is the creation of a common course or the offering of extra points in the FIG courses.

One idea for getting more students involved is to create a competition that involves students from our College and high schools within a 30-mile radius (especially the new magnet high school of engineering and science on our campus) in which the College students work side by side with the high school students in team projects as in F.I.R.S.T. Robotics or the mouse trap race car project at the University of Kansas.

To increase interest and therefore retention, we are also considering the creation of a Collegewide senior project presentation week. Each major would present their projects on a particular day, and students from all majors would have the opportunity to attend and critique the various projects. While we already encourage other students to attend various presentations, we believe we could do it in a grander manner to attract more students. We could also remind students of an added benefit to attendance; they would witness first-hand what is involved in an outstanding project and the caliber of work required for such outcomes. So many students have never seen professional-level presentations that we must give them the experience. And students from all the majors would see what professionals in other disciplines do. Along the same lines, we could encourage the creation of interdisciplinary teams and the presentation of multidisciplinary projects in emulation of the workplace.

\section{Conclusions}

Recognizing that we had a problem in retaining students in our three smallest majors along with TBD students, we resolved to improve the situation. We revised the common course, ET 111, to provide greater opportunities for bonding among the students in those programs. To further encourage those students to function as a group, we decided to place them in the FIG courses and have now begun to see the groups cohering and enrollment numbers stabilizing.

A positive experience during the first semester, including satisfactory academic progress, and a social and academic network will position students more advantageously for success. Freshmen are provided with assistance in adjusting to college life, the opportunity to build relationships with faculty at an earlier stage in their program, and the chance to make connections with their peers in a nurturing, non-threatening, and supportive atmosphere. Students are also enrolled in at least one course in their major to provide hands-on experience, create motivation, and learn problem solving techniques. These combined efforts help students set educational goals and make better informed career choices. 
We intend to continue our efforts by creating a strong peer-mentoring program and will seek other techniques that create opportunities for academic, interpersonal, and administrative engagement of and with our students to build the confidence for potential success.

\section{References}

${ }^{1}$ McDonald, 'Enhancing the Recruitment and Retention of First-Year Students with Improved Career Selection Opportunities,' 1995 ASEE/IEEE Frontiers in Education Conference Proceeding.s

${ }^{2}$ Woolston, D., Shook, K., and Wilson, J., 'Same Problem, Different Solutions: Attempts at Improving Retention in Engineering at a Research vs. a Teaching University,' 1995 ASEE/IEEE Frontiers in Education Conference Proceedings.

${ }^{3}$ Khan, F., and Siddique, B., 'An NSF Pilot Project on Minority Student Retention'

${ }^{4}$ Brower, T., and Cornachion, H., 'Women in Engineering Technology: Where are they?'

${ }^{5}$ Seymour, E., and Hewitt, N., 'Talking about Leaving: Factor Contributing to High Attrition Rates Among Science, Mathematics and Engineering Undergraduates,' Boulder, Colorado: University of Colorado.

${ }^{6}$ Canistraro, H., Katz, P., Girouard, J., Lankford, A., and Dannenhoffer, J., 'Revision of the Freshmen Level Course, Introduction to Engineering Technology at the Ward College of Technology,' Proceedings, American Society for Engineering Educators, Charlotte, NC, 1999.

${ }^{7}$ Canistraro, C., and Townsend, S., 'Recruiting and Retaining Faculty and Managing Diverse Majors in Four Year Schools of Engineering Technology,' 1999 ASEE Annual Conference, Charlotte, NC, June 1999.

${ }^{8}$ Segal, N., and Townsend, S., 'Word Problems and Problems with Words,' 2001 ASEE Annual Conference, Albuquerque, NM, June 2001.

${ }^{9}$ Segal, N., and Townsend, S., 'Teaching Problem Solving in an Integrated Mathematics Writing Curriculum,' 2002 ASEE Annual Conference, Montréal, Québec, June 2002. 